\title{
Prevalence of Hypertension and Its Associated Risk Factors among 34,111 HAART Naïve HIV-Infected Adults in Dar es Salaam, Tanzania
}

\author{
Marina Njelekela, ${ }^{1}$ Alfa Muhihi, ${ }^{2,3}$ Akum Aveika, ${ }^{2}$ Donna Spiegelman, ${ }^{4,5}$ Claudia Hawkins, ${ }^{6}$ \\ Catharina Armstrong, ${ }^{7}$ Enju Liu, ${ }^{8,9}$ James Okuma, ${ }^{8}$ Guerino Chalamila, ${ }^{2}$ Sylvia Kaaya, ${ }^{10}$ \\ Ferdinand Mugusi, ${ }^{11}$ and Wafaie Fawzi ${ }^{4,8,9}$ \\ ${ }^{1}$ Department of Physiology, Muhimbili University of Health and Allied Sciences, Dar es Salaam, Tanzania \\ ${ }^{2}$ Management and Development for Health, HIV/AIDS Care and Treatment Program, Dar es Salaam, Tanzania \\ ${ }^{3}$ Africa Academy for Public Health, P.O. Box 79810, Dar es Salaam, Tanzania \\ ${ }^{4}$ Department of Epidemiology, Harvard TH Chan School of Public Health, Boston, MA, USA \\ ${ }^{5}$ Department of Biostatistics, Harvard TH Chan School of Public Health, Boston, MA, USA \\ ${ }^{6}$ Feinberg School of Medicine, Northwestern University, Chicago, IL, USA \\ ${ }^{7}$ Tufts University School of Medicine, Boston, MA, USA \\ ${ }^{8}$ Department of Nutrition, Harvard TH Chan School of Public Health, Boston, MA, USA \\ ${ }^{9}$ Department of Global Health and Population, Harvard TH Chan School of Public Health, Boston, MA, USA \\ ${ }^{10}$ Department of Psychiatry and Mental Health, Muhimbili University of Health and Allied Sciences, Dar es Salaam, Tanzania \\ ${ }^{11}$ Department of Internal Medicine, Muhimbili University of Health and Allied Sciences, Dar es Salaam, Tanzania
}

Correspondence should be addressed to Marina Njelekela; madaula@yahoo.com

Received 30 August 2016; Accepted 29 September 2016

Academic Editor: Tomohiro Katsuya

Copyright ( 2016 Marina Njelekela et al. This is an open access article distributed under the Creative Commons Attribution License, which permits unrestricted use, distribution, and reproduction in any medium, provided the original work is properly cited.

Background. Elevated blood pressure has been reported among treatment naïve HIV-infected patients. We investigated prevalence of hypertension and its associated risk factors in a HAART naïve HIV-infected population in Dar es Salaam, Tanzania. Methods. A cross-sectional analysis was conducted among HAART naïve HIV-infected patients. Hypertension was defined as systolic blood pressure $(\mathrm{SBP}) \geq 140 \mathrm{mmHg}$ and/or diastolic blood pressure (DBP) $\geq 90 \mathrm{mmHg}$. Overweight and obesity were defined as body mass index (BMI) between $25.0-29.9 \mathrm{~kg} / \mathrm{m}^{2}$ and $\geq 30 \mathrm{~kg} / \mathrm{m}^{2}$, respectively. We used relative risks to examine factors associated with hypertension. Results. Prevalence of hypertension was found to be $12.5 \%$. After adjusting for possible confounders, risk of hypertension was $10 \%$ more in male than female patients. Patients aged $\geq 50$ years had more than 2 -fold increased risk for hypertension compared to 30-39-years-old patients. Overweight and obesity were associated with 51\% and $94 \%$ increased risk for hypertension compared to normal weight patients. Low CD4+ T-cell count, advanced WHO clinical disease stage, and history of TB were associated with 10\%, 42\%, and 14\% decreased risk for hypertension. Conclusions. Older age, male gender, and overweight/obesity were associated with hypertension. Immune suppression and history of TB were associated with lower risk for hypertension. HIV treatment programs should screen and manage hypertension even in HAART naïve individuals.

\section{Introduction}

The introduction of Highly Active Antiretroviral Therapy (HAART) marked a milestone in the prognosis, course of infection, and quality of life for people living with human immunodeficiency virus (HIV) in both developed and developing countries $[1,2]$. Cardiovascular diseases (CVDs) are increasingly observed in HIV-infected people especially in developed countries where people with HIV/AIDS are living much longer [3]. In addition to increased patient longevity, 
data indicate that increased incidence of CVDs is also attributable to HIV infection itself and use of HAART $[4,5]$.

Generally, the impact of HIV and HAART on hypertension remains controversial. A recent systematic review with meta-analysis of over 44,000 HIV-infected patients has shown the mean systolic blood pressure and risk of hypertension to be significantly higher among HAART exposed compared to HAART naïve individuals [6]. Studies conducted in Europe and US found higher rates of hypertension among HIV-infected adults on HAART than uninfected adults [7] with others indicating no difference $[8,9]$. However, results from a multicenter AIDS cohort study of men with blood pressure measurements between 1984 and 2003 indicated a significant association between prolonged use of HAART with systolic hypertension [10].

A systematic review and meta-analysis from sub-Saharan Africa found lower blood pressure levels among HIV-infected than uninfected adults [11]. Another large, population-based study from South Africa indicated hypertension to be less common among HIV-infected adults [12]. However, both studies from Africa lacked data on long-term HAART use. Hypertension may develop as a result of long-term HAART use due to weight gain, drug toxicity, and some immunerelated phenomenon. A study conducted in Nigeria reported no association between HIV infection and HAART status with hypertension [13]. However, this study had a relatively small sample size and was of short duration of HAART in the treated group. Reports from other studies indicate a slightly higher prevalence of CVD risk factors among HIV-infected individuals, especially those on HAART $[14,15]$.

Data from resource-limited settings among non-HIVinfected people has indicated increasing rates of traditional risk factors associated with CVD such as hypertension, diabetes mellitus, and dyslipidemia, primarily as a result of obesity and urbanization [16-18]. These risk factors contribute to a significant proportion of overall disease burden in Africa $[19,20]$. The prevalences of metabolic syndrome and hypertension are reported to be increasing in Africa $[18,21]$. Metabolic syndrome is defined as a cluster of several cardiometabolic risk factors, including abdominal obesity, hyperglycemia, dyslipidemia, and elevated blood pressure [22].

In view of existing gap of knowledge and scarcity of data on the prevalence and correlates of CVD risk factors especially among HIV-infected population in resource-limited settings, we conducted this analysis to assess the prevalence of hypertension and its associated risk factors in a cohort of HIV-infected, HAART naïve in Dar es Salaam, Tanzania.

\section{Methods}

2.1. Study Design, Site, and Population. Data for this crosssectional analysis were collected at 12 HIV Care and Treatment Clinics (CTCs) affiliated to Management and Development for Health (MDH) and supported by President's Emergency Plan for AIDS Relief (PEPFAR) in Dar es Salaam, Tanzania. The MDH-PEPFAR program was established in 2004 and provided infrastructure, laboratory, and technical support to HIV CTCs, Prevention of Mother to Child
Transmission (PMTCT) clinics, and Tuberculosis facilities in Dar es Salaam region. Dar es Salaam has a population of more than four million people with an HIV prevalence of 6.9\% [23]. This analysis is comprised of patients who had blood pressure (BP) measurement taken, were $\geq 15$ years of age, and were nonpregnant at the time of enrolment.

2.2. Blood Pressure Measurement. Blood pressure measurements were taken on arrival to the clinic using a standardized digital blood pressure measuring machine (AD Medical Inc.). Three blood pressure readings were taken on the left upper arm with the participant in a seated position following at least 5 to 10 minutes of rest. The average of the three readings was used in this analysis.

2.3. Anthropometric Measurement. Body weight and height were taken following standard procedures. Body weight (to the nearest $0.5 \mathrm{~kg}$ ) was taken with the participant in light clothing using a SECA scale. Height (to the nearest $0.5 \mathrm{~cm}$ ) was measured using a stadiometer with participants wearing no shoes. Body mass index (BMI) was then calculated as weight in kilograms divided by square of height in meters $\left(\mathrm{kg} / \mathrm{m}^{2}\right)$. Overweight was defined as BMI between 25.0 and $29.9 \mathrm{~kg} / \mathrm{m}^{2}$ and obesity as BMI $\geq 30 \mathrm{~kg} / \mathrm{m}^{2}$.

2.4. Clinical and Laboratory Procedures. Clinical care of all $\mathrm{HIV}$-infected patients at $\mathrm{MDH}$-supported CTCs follows the Tanzanian National guidelines for management of HIV patients [24]. Following HIV diagnosis, patients were enrolled in the CTC clinic and had WHO clinical stage, CD4+ T-cell count, and HAART eligibility status determined. Eligible patients were subsequently initiated on HAART after adherence counseling and were followed up by physicians and nurses at two weeks after HAART initiation for assessment and management of any toxicity. They were then assessed at monthly clinic visits. Patients not yet meeting HAART initiation criteria were followed up at 6 monthly HIV care and monitoring visits.

Blood samples were collected and separated within 6 to 8 hours of specimen collection and stored at -80 -degree centigrade for four weeks. Batch testing of samples was performed by a senior technician at Muhimbili University of Health and Allied Sciences (MUHAS). Daily calibration of instruments was done following standardized procedures. The MUHAS laboratory participates in the College of American Pathologists proficiency testing programs where three general chemistry panels including lipids and two calibration verification panels are taken annually. Immunologic assessment with CD4+ T-cell count was performed using the FACS Calibur System (Becton Dickinson, San Jose, California, USA).

TB screening was performed to all patients at baseline using a TB screener form containing five questions:

(i) History of cough for $\geq 2$ weeks

(ii) History of hemoptysis

(iii) History of fever for $\geq 2$ weeks

(iv) Noticeable weight loss for new patients or weight loss $\geq 3.0 \mathrm{~kg}$ in a month

(v) Excessive night sweats for $\geq 2$ weeks. 
All patients who were screened positive for TB (had at least one of the abovementioned symptoms) had a chest radiograph and sputum analysis conducted for diagnosis of TB.

2.5. Data Collection and Management. Physicians and nurses completed standard forms capturing demographic, clinical, laboratory, and therapeutic information at baseline and follow-up visits. Data reviewers were stationed at each clinic to ensure completeness of data recording by physicians and nurses. Data collected was then entered into a secure computerized database using unique patient identifiers. The database was updated daily by dedicated data entry clerks trained to use a prospective data collection instrument.

Weekly quality assurance checks were performed by the data management team to ensure data accuracy. Data collected for this analysis included baseline demographics, age, weight, height, blood pressure, midupper arm circumference (MUAC), body mass index (BMI), WHO clinical disease stage, and history of prior or current TB.

2.6. Outcomes and Definitions. The primary outcome of interest was hypertension, which was defined according to the guidelines for management of hypertension in HIV. The Joint National Committee VII (JNC VII) report released in 2003 categorizes blood pressure as follows: normal blood pressure (systolic (SBP)/diastolic (DBP) < 120/80 mmHg); prehypertension (SBP 120-139 mmHg or DBP $80-89 \mathrm{mmHg}$ ); stage 1 hypertension (SBP $140-159 \mathrm{mmHg}$ or DBP $90-99 \mathrm{mmHg}$ ); and stage 2 hypertension (SBP $\geq 160 \mathrm{mmHg}$ or $\mathrm{DBP} \geq$ $100 \mathrm{mmHg}$ ) [25].

2.7. Ethical Approval. The study was approved by institutional review boards for human research at Harvard $\mathrm{TH}$ Chan School of Public Health and the Research Ethics Review Committee of the Muhimbili University of Health and Allied Sciences. Patients were recruited for participation and enrolled in the MDH-supported CTCs following written informed consent.

2.8. Statistical Analysis. Sociodemographic and cardiometabolic characteristics of the study population were described using mean (SD) or percentage. To examine the factors associated with hypertension, prevalence ratios (relative risks) were estimated using Generalized Estimating Equations (GEE) with the log link function and the binomial variance $[26,27]$. All multivariate analyses were adjusted for age $(<30$, 30-39, 40-49, and $\geq 50$ years); gender (male/female); district (Ilala, Kinondoni, and Temeke); calendar year and season of enrolment; BMI (underweight, normal weight, overweight, and obesity); CD4+ T-cell count $(<350,350-<500$, and $\geq 500)$; WHO clinical disease stage (I, II, III, and IV); history of TB; and current TB/HIV coinfected. The median score test was used to assess the significance of any trends observed and a Wald test was used for binary variables. The missing indicator method was used in the multivariate models [28]. Statistical analyses were performed with the statistical software package SAS (release 9.2). All tests were two-sided, and a $p<0.05$ was considered statistically significant.
TABLE 1: Sociodemographic and clinical characteristics of the participants.

\begin{tabular}{|c|c|}
\hline Characteristic & Mean \pm SD or $N(\%)$ \\
\hline Age (years) & $36.6 \pm 9.5$ \\
\hline \multicolumn{2}{|l|}{ Age categories } \\
\hline$<30$ & $7760(22.9)$ \\
\hline $30-39$ & $14877(43.9)$ \\
\hline $40-49$ & $7964(23.4)$ \\
\hline$\geq 50$ & $3317(9.8)$ \\
\hline \multicolumn{2}{|l|}{ Gender } \\
\hline Male & $11199(32.8)$ \\
\hline Female & $22912(67.2)$ \\
\hline$B M I\left(k g / m^{2}\right)$ & $21.4 \pm 4.8$ \\
\hline \multicolumn{2}{|l|}{ BMI-defined categories } \\
\hline Underweight $\left(\mathrm{BMI}<18.5 \mathrm{~kg} / \mathrm{m}^{2}\right)$ & 9235 (27.6) \\
\hline Normal (BMI 18.5-24.9 kg/m²) & $18160(54.4)$ \\
\hline Overweight (BMI $25.0-29.9 \mathrm{~kg} / \mathrm{m}^{2}$ ) & $4322(12.9)$ \\
\hline Obesity (BMI $\left.\geq 30 \mathrm{~kg} / \mathrm{m}^{2}\right)$ & $1693(5.1)$ \\
\hline \multicolumn{2}{|l|}{ CD $4+$ cell count $($ cells $/ \mu L)$} \\
\hline$<350$ & $23050(75.5)$ \\
\hline $350-<500$ & $3748(12.3)$ \\
\hline$\geq 500$ & $3720(12.2)$ \\
\hline \multicolumn{2}{|l|}{ WHO clinical disease stage } \\
\hline Stage I & $4910(14.9)$ \\
\hline Stage II & $6228(18.9)$ \\
\hline Stage III & $15128(45.9)$ \\
\hline Stage IV & $6686(20.3)$ \\
\hline \multicolumn{2}{|l|}{ History of $T B$ infection } \\
\hline Yes & $7739(23.3)$ \\
\hline No & $25539(76.7)$ \\
\hline \multicolumn{2}{|l|}{ Current TB/HIV coinfection } \\
\hline Yes & $3245(9.7)$ \\
\hline No & $30246(90.3)$ \\
\hline
\end{tabular}

BMI: body mass index; BP: blood pressure; CD4+: cluster of differentiation 4; HIV: human immunodeficiency virus; TB: tuberculosis; WHO: World Health Organization.

\section{Results}

3.1. Sociodemographic and Clinical Characteristics of the Study Population. A total of 34,111 nonpregnant, HAART naïve patients who had blood pressure measurement taken were included in the analysis. The baseline demographic and clinical characteristics of the study patients are summarized in Table 1. The mean age and BMI of the patients were $36.6 \pm 9.5$ years and $21.4 \pm 4.8 \mathrm{~kg} / \mathrm{m}^{2}$, respectively, and women constituted two-thirds of the study participants. Three-quarters $(75.5 \%)$ of the participants had CD4+ T-cell count of less than 350 cells $\mu \mathrm{L}$ and two-thirds (66.2\%) had a WHO clinical disease stage III or stage IV. Nearly quarter of the participants $(23.3 \%)$ had a positive history of TB and about one-tenth $(9.7 \%)$ were currently TB/HIV coinfected receiving anti-TB treatment. 
TABLE 2: Mean systolic and diastolic blood pressures and prevalence of hypertension.

\begin{tabular}{lc}
\hline Variable & Mean \pm SD or N (\%) \\
\hline Systolic blood pressure, SBP $(\mathrm{mmHg})$ & $114.1 \pm 18.1$ \\
Diastolic blood pressure, DBP $(\mathrm{mmHg})$ & $73.1 \pm 12.9$ \\
Blood pressure categories & \\
Normal BP & $19859(58.2)$ \\
Prehypertension & $9967(29.2)$ \\
Stage 1 hypertension & $2668(7.8)$ \\
Stage 2 hypertension & $1617(4.7)$ \\
Hypertension & \\
Yes & $4285(12.5)$ \\
No & $29826(87.4)$ \\
\hline
\end{tabular}

BP: blood pressure; SD: standard deviation.

3.2. Blood Pressure and Prevalence of Hypertension. Results on blood pressure measurements are summarized in Table 2. The mean systolic and diastolic blood pressures were $114.1 \pm$ $18.1 \mathrm{mmHg}$ and $73.1 \pm 12.9 \mathrm{mmHg}$, respectively. More than half $(58.2 \%)$ of the patients had their blood pressure measurement within the normal range and more than quarter (29.2\%) had their blood pressure in the prehypertension range. The prevalence of hypertension (combined stages 1 and 2 hypertension) found in this study population was $12.5 \%$.

\subsection{Sociodemographic and Clinical Characteristics Associated} with Hypertension. The various sociodemographic and clinical factors associated with hypertension among study patients are summarized in Table 3 . Older age ( $\geq 50$ years), male gender, overweight and obesity, CD4+ T-cell count $(\geq 500$ cells $/ \mu \mathrm{L})$, and WHO clinical disease stage I were all significantly associated with higher prevalence of hypertension. WHO clinical disease stage IV, history of $\mathrm{TB}$, and being TB/HIV coinfected were significantly associated with a lower prevalence of hypertension.

3.4. Relationship between Age, Gender, and Body Mass Index with Prevalence of Hypertension. Results for univariate and multivariate analyses for risk factors associated with hypertension are summarized in Table 4. After adjusting for district (Ilala, Kinondoni, and Temeke), calendar year and season of enrolment, age ( $<30,30-39,40-49$, and $\geq 50$ years), gender (male/female), BMI (underweight, normal weight, overweight, and obesity), CD4+ T-cell count $(<350,350-$ $<500$, and $\geq 500$ ), WHO clinical disease stage (I, II, III, and IV), history of $\mathrm{TB}$, and current $\mathrm{TB} / \mathrm{HIV}$ coinfected, patients aged $40-49$ years and those aged $\geq 50$ years had a $43 \%$ [ARR 1.43 (95\% CI 1.33, 1.53)] and 2-fold [ARR 2.52 (95\% CI 1.92, 3.30)] increased risk for hypertension compared to patients aged 30-39 years. Male patients had 10\% [ARR 1.10 (95\% CI 1.04, 1.17)] increased risk of hypertension compared to female patients. Overweight and obesity were associated with 51\% [ARR 1.51 (95\% CI 1.40, 1.62)] and 94\% [ARR $1.94(95 \%$ CI $1.78,2.12)]$, respectively, increased risk for hypertension compared to normal weight patients.

Prevalence of hypertension was significantly lower in patients with immune suppression at baseline. Hypertension was $10 \%$ (ARR $0.90 ; 95 \%$ CI $0.83,0.98$ ) lower in patients with CD4+ T-cell count $<350$ cells $/ \mu \mathrm{L}$ compared to those with CD4+ T-cell count $\geq 500$ cells $/ \mu$ L. Similarly, patients with advanced WHO clinical disease stage had significantly lower risk of hypertension. Patients with WHO clinical disease stages II and III had $12 \%$ and $28 \%$ decreased risk for hypertension compared to patients with stage I disease. WHO clinical disease stage IV was associated with $42 \%$ decreased risk for hypertension compared to stage I disease.

History of TB was observed to be protective against hypertension. Patients with history of TB had statistically significant $14 \%$ decreased risk for hypertension compared to patients with no history of TB. On the contrary, patients who were current TB/HIV coinfected had a nonsignificant $5 \%$ increased risk for hypertension.

\section{Discussion}

We report an appreciable prevalence of hypertension in a cohort of HAART naïve HIV-infected adults in Tanzania. We found significant associations between older age, male gender, and overweight/obesity with higher prevalence of hypertension. Furthermore, the prevalence of hypertension was inversely associated with level of immune suppression. This study is one among few published studies examining the prevalence of hypertension as one of the key risk factors associated with CVD in HIV-infected population from resourcelimited settings.

Arterial hypertension is a major CVD risk factor. However, there are few studies that have analyzed the relationship between blood pressure and HIV infection $[7,8]$. In our study, we observed a prevalence of hypertension (combined stages 1 and 2) of $12.5 \%$. The prevalence of hypertension observed in this study is lower than that reported by studies conducted elsewhere in Africa [13,29-31]. Although we did not compare the prevalence of hypertension to patients on HAART, several studies have reported higher prevalence of hypertension among HIV-infected patients on HAART [29, 30, 32, 33], supporting that HAART is associated with hypertension. Other studies have found no association between HAART use and hypertension $[9,34]$. Ogunmola et al. reported no significant difference in the prevalence of hypertension, mean SBP, and mean DBP between HIV-negative, HIV-positive on HAART, and HIV-positive HAART naïve patients [13].

The variability in the prevalence of hypertension observed in our study to that reported by other studies may be explained by several factors, one of them being the cut-off for defining hypertension. For example, in most of these studies, their cut-off point was $160 / 95 \mathrm{mmHg}$ compared to the definition we used (SBP $\geq 140 \mathrm{mmHg}$ and/or DBP $\geq$ $90 \mathrm{mmHg}$ ). Other factors such as differences in age, ethnicity, and levels of obesity may also explain the variations in the observed prevalence of hypertension. In our study, inclusion of HAART naïve patients only may partly explain the observed low prevalence of hypertension. Further analysis comparing with patients on HAART is warranted.

Several mechanisms have been proposed to explain the link between HIV and CVD [31, 35]. HIV infection, chronic inflammation, hypercoagulability, and platelet activation 
TABLE 3: Sociodemographic and clinical characteristics associated with hypertension.

\begin{tabular}{|c|c|c|c|c|}
\hline Parameter & $\begin{array}{c}\text { All } \\
N=34,111\end{array}$ & $\begin{array}{c}\text { Normotensive } \\
\quad N(\%)\end{array}$ & $\begin{array}{c}\text { Hypertensive } \\
N(\%)\end{array}$ & $p$ value \\
\hline Age (years) & & & & $<0.001$ \\
\hline$<30$ & 7760 & $7131(91.9 \%)$ & $629(8.1 \%)$ & \\
\hline $30-39$ & 14877 & $3289(89.3 \%)$ & $1588(10.7 \%)$ & \\
\hline $40-49$ & 7964 & $6756(84.8 \%)$ & $1208(15.2 \%)$ & \\
\hline$\geq 50$ & 3317 & $2505(75.5 \%)$ & $813(24.5 \%)$ & \\
\hline Gender & & & & $<0.001$ \\
\hline Male & 11199 & $8423(75.2 \%)$ & $2776(24.8 \%)$ & \\
\hline Female & 22912 & $21409(93.4 \%)$ & $1503(6.6 \%)$ & \\
\hline BMI-defined obesity & & & & $<0.001$ \\
\hline Underweight $\left(\mathrm{BMI}<18.5 \mathrm{~kg} / \mathrm{m}^{2}\right)$ & 9235 & $8643(93.6 \%)$ & $592(6.4 \%)$ & \\
\hline Normal (BMI 18.5-24.9kg/m²) & 18160 & $15884(87.5 \%)$ & $2276(12.5 \%)$ & \\
\hline Overweight (BMI $25.0-29.9 \mathrm{~kg} / \mathrm{m}^{2}$ ) & 4322 & $3440(79.6 \%)$ & $882(20.4 \%)$ & \\
\hline Obesity $\left(\mathrm{BMI} \geq 30 \mathrm{~kg} / \mathrm{m}^{2}\right)$ & 1693 & $1228(72.5 \%)$ & $465(27.5 \%)$ & \\
\hline CD4+ cell count $($ cells $/ \mu L)$ & & & & $<0.001$ \\
\hline$<350$ & 23050 & $20414(88.6 \%)$ & $2636(11.4 \%)$ & \\
\hline $350-<500$ & 3748 & $3177(84.8 \%)$ & $571(15.2 \%)$ & \\
\hline$\geq 500$ & 3720 & $3120(83.9 \%)$ & $600(16.1 \%)$ & \\
\hline WHO clinical disease stage & & & & $<0.001$ \\
\hline Stage I & 4910 & $3982(81.1 \%)$ & $928(18.9 \%)$ & \\
\hline Stage II & 6228 & $5234(84.0 \%)$ & $994(16.0 \%)$ & \\
\hline Stage III & 15128 & $13392(88.5 \%)$ & $1736(11.5 \%)$ & \\
\hline Stage IV & 6686 & $6139(91.8 \%)$ & $547(8.2 \%)$ & \\
\hline History of $T B$ & & & & $<0.001$ \\
\hline Yes & 7739 & $6993(90.4 \%)$ & $746(9.6 \%)$ & \\
\hline No & 25539 & $22097(86.5 \%)$ & $3442(13.5 \%)$ & \\
\hline Current TB/HIV coinfection & & & & $<0.001$ \\
\hline Yes & 3245 & $2940(90.6 \%)$ & $305(9.4 \%)$ & \\
\hline No & 30246 & $26345(87.1 \%)$ & $3901(12.9 \%)$ & \\
\hline
\end{tabular}

BMI: body mass index; CD4+: cluster of differentiation 4; HIV: human immunodeficiency virus; TB: tuberculosis; WHO: World Health Organization.

mediated by HIV infection itself contribute to endothelial dysfunction and subsequent increased CVD risk $[15,36]$. It has been proposed that HIV influences endothelial function via activated monocytes and resultant cytokine secretion and via a direct effect of the secreted HIV proteins tat and gp120 [37]. Another mechanism involves free radical physiology, where excess nitric oxide reacts with oxygen radicals to produce peroxynitrite, which then causes oxidative damage to the vascular endothelium, and decreased flow mediated dilation [38]. Use of HAART in patients infected with HIV1 has been shown to reduce markers of endothelial function and coagulation $[15,31,35]$.

We observed a significant association between older age, male gender, and overweight/obesity and increased risk for hypertension. These findings are in agreement with other studies conducted among HIV-infected individuals. In addition to HAART exposure, these studies found male gender, advancing age, high body mass index, greater waist circumference, HIV-hepatitis $\mathrm{C}$ coinfection, and ethnicity to be associated with increased risk of developing hypertension and coronary heart disease (CHD) in HIV-infected patients $[7,33]$. We have also demonstrated increased mortality among male patients with HIV in one of our publications [39].

We observed an inverse association between advanced HIV disease (defined as low CD4+ T-cell count and advanced WHO clinical disease stage) and risk for hypertension. Participants with low CD4+ T-cell count $<350$ cells $/ \mu \mathrm{L}$ and those with WHO clinical disease stage IV had lower risk for hypertension. This finding is contrary to results from other studies which show that low CD4+ T-cell count is a risk for CVD [40-43]. The proposed mechanism for association between low immunity and risk of CVD is that chronic inflammation that accompanies uncontrolled 
TABLE 4: Univariate and multivariate adjusted demographic, body mass index, and clinical and immunological factors associated with prevalence of hypertension.

\begin{tabular}{|c|c|c|c|c|}
\hline & $\begin{array}{c}\text { Unadjusted RR } \\
(95 \% \mathrm{CI})\end{array}$ & $p$ value & $\begin{array}{c}\text { Adjusted RR } \\
(95 \% \mathrm{CI}) \\
\end{array}$ & $p$ value \\
\hline Age group (years) & & 0.002 & & $<0.001$ \\
\hline $15-29$ & $0.76(0.70-0.83)$ & & $0.74(0.67-0.81)$ & \\
\hline $30-39$ & Reference & & Reference & \\
\hline $40-49$ & $1.42(1.32-1.52)$ & & $1.43(1.33-1.53)$ & \\
\hline 50 & $2.30(2.14-2.49)$ & & $2.52(1.92-3.30)$ & \\
\hline Gender & & $<0.001$ & & 0.002 \\
\hline Female & Reference & & Reference & \\
\hline Male & $1.11(1.05-1.18)$ & & $1.10(1.04-1.17)$ & \\
\hline BMI-defined obesity & & 0.003 & & $<0.001$ \\
\hline Underweight $\left(\mathrm{BMI}<18.5 \mathrm{~kg} / \mathrm{m}^{2}\right)$ & $0.51(0.47-0.56)$ & & $0.57(0.52-0.62)$ & \\
\hline Normal (BMI $18.5-24.9 \mathrm{~kg} / \mathrm{m}^{2}$ ) & Reference & & Reference & \\
\hline Overweight (BMI $25.0-29.9 \mathrm{~kg} / \mathrm{m}^{2}$ ) & $1.63(1.52-1.74)$ & & $1.51(1.40-1.62)$ & \\
\hline Obesity (BMI $\geq 30 \mathrm{~kg} / \mathrm{m}^{2}$ ) & $2.19(2.00-2.38)$ & & $1.94(1.78-2.12)$ & \\
\hline CD $4+$ cell count $($ cells/ $\mu L)$ & & $<\mathbf{0 . 0 0 1}$ & & 0.003 \\
\hline$<350$ & $0.49(0.44-0.54)$ & & & \\
\hline $350-<500$ & $0.77(0.72-0.82)$ & & & \\
\hline$>500$ & Reference & & Reference & \\
\hline WHO Clinical disease stage & & $<0.001$ & & $<0.001$ \\
\hline Stage I & Reference & & Reference & \\
\hline Stage II & $0.83(0.77-0.90)$ & & $0.88(0.81-0.96)$ & \\
\hline Stage III & $0.58(0.54-0.63)$ & & $0.72(0.66-0.78)$ & \\
\hline Stage IV & $0.42(0.38-0.47)$ & & $0.58(0.52-0.64)$ & \\
\hline History of $T B$ & & $<0.001$ & & $<0.001$ \\
\hline Yes & $0.72(0.66-0.77)$ & & $0.86(0.78-0.94)$ & \\
\hline No & Reference & & Reference & \\
\hline Current TB/HIV coinfection & & 0.410 & & 0.420 \\
\hline Yes & $1.08(0.89-1.18)$ & & $1.05(0.92-1.20)$ & \\
\hline No & Reference & & Reference & \\
\hline
\end{tabular}

BMI: body mass index; CI: confidence interval; HIV: human immune deficiency virus; RR: risk ratio; TB: tuberculosis; WHO: World Health Organization. The final model for multivariate analyses included district (Ilala, Kinondoni, and Temeke), calendar year and season of enrolment, age $(<30,30-39,40-49$, and $\geq 50$ years), gender (male/female), BMI (underweight, normal weight, overweight, and obesity), CD4+ cell count ( $<350,350-<500$, and $\geq 500)$, WHO clinical disease stage (I, II, III, and IV), history of TB, and current TB/HIV coinfected. The median score test was used to assess the significance of any trends observed and a Wald test was used for binary variables.

or more advanced HIV disease is associated with elevated levels of serum markers of inflammation and increased levels of activated CD4+ T-cells and proinflammatory cytokines that destabilize atherosclerotic plaques leading to CVD event $[42,44]$.

Participants with history of TB had a 10\% decreased risk for hypertension, but this protective effect was not observed among those who were currently TB/HIV coinfected. Few studies have explored the association between TB and CVD risk and have reported contradicting conclusions. An age and sex matched study conducted by Giral et al. [45] showed that past TB was not associated with a higher prevalence of atherosclerotic lesions in patients with hypercholesterolemia patients, while $\mathrm{Wu}$ et al. [46] reported that non-CNS TB does not increase the risk of subsequent ischemic stroke. In contrary, Sheu et al. [47] found patients with a diagnosis of $\mathrm{TB}$ to be at an increased risk for ischemic stroke. Our finding of history of TB conferring protective effect against hypertension further increases the need for further research to investigate the relationship between TB and CVD and its risk factors.

While the major strength of this analysis is its large sample size, it has several limitations worth mentioning. First, the cross-sectional design of the study does not provide proof of causal association between HIV, immune suppression, and the development of hypertension. Secondly, the analysis was limited to hypertension and obesity. We did not evaluate the contribution of other conversional risk factors such as diabetes, lipid profile, smoking, alcohol drinking, physical activity, dietary, and other lifestyle related factors. Third, 
inclusion of HAART naïve only in the analysis made it impossible to make comparisons with counterpart HIV-infected patients on HAART or HIV-negative as in other studies $[13,30]$. Fourth, selection bias might have been introduced by inclusion of patients who attended MDH-supported CTCs only, thus affecting generalizability of the findings. However, $\mathrm{MDH}$-supported CTCs are publicly accessible and patients attending these clinics may be similar to those attending other public health facilities CTCs in Dar es Salaam. Despite the abovementioned limitations, this study remains an important analysis of blood pressure and its associated risk factors in a large cohort of HIV-infected HAART naive patients from resource-limited settings.

In conclusion, we observed that older age, male gender, and BMI-defined overweight/obesity were significantly associated with higher prevalence of hypertension even after adjusting for potential confounders. Furthermore, immune suppression (defined by low CD4+ T-cell count and advanced WHO clinical diseased stage) and history of TB were associated with decreased risk for hypertension. Screening and regular monitoring for complications associated with use of HAART among HIV-infected people have been a routine clinical practice. HIV treatment programs are recommended to conduct routine screening and monitoring for hypertension and other CVD risk factors even prior to initiation of HAART especially among healthy-looking individuals. Traditional hypertension control measures such as physical exercise, weight control, and healthy diet should be recommended to HIV-infected individuals. Further research is warranted to investigate the association between TB, immune suppression, and CVD risk observed in this study.

\section{Competing Interests}

The authors declare that they have no competing interests.

\section{Authors' Contributions}

Wafaie Fawzi, Donna Spiegelman, Guerino Chalamila, Sylvia Kaaya, and Ferdinand Mugusi conceived and designed the experiment. Wafaie Fawzi, Donna Spiegelman, Guerino Chalamila, Sylvia Kaaya, and Ferdinand Mugusi performed the experiment. Marina Njelekela, Akum Aveika, Enju Liu, and Alfa Muhihi analyzed the data. Wafaie Fawzi, Donna Spiegelman, Catharina Armstrong, and James Okuma contributed reagents/materials/analysis tools. Wafaie Fawzi, Donna Spiegelman, Guerino Chalamila, Sylvia Kaaya, Ferdinand Mugusi, Marina Njelekela, Alfa Muhihi, Claudia Hawkins, Enju Liu, Catharina Armstrong, and James Okuma wrote the paper. All authors read and approved the final version.

\section{Acknowledgments}

The PEPFAR funded National HIV Care and Treatment in Dar es Salaam program was implemented by Management and Development for Health $(\mathrm{MDH})$ in collaboration with Dar es Salaam City Council, Harvard TH Chan School of Public Health (HSPH), Muhimbili University of Health and Allied Sciences (MUHAS) and the Ministry of Health,
Community Development, Gender, Elderly and Children in Tanzania. The authors thank the Fogarty International Fellowship Grant through MUHAS-Harvard Collaboration for supporting Dr. Marina Njelekela during data analysis and manuscript writing. The authors also extend their gratitude to all the study participants as well as staff of the MDHsupported care and treatment sites who contributed tirelessly to making these findings known.

\section{References}

[1] O. O. Oguntibeju, "Quality of life of people living with HIV and AIDS and antiretroviral therapy," HIV/AIDS-Research and Palliative Care, vol. 4, pp. 117-124, 2012.

[2] J. Beard, F. Feeley, and S. Rosen, "Economic and quality of life outcomes of antiretroviral therapy for HIV/AIDS in developing countries: a systematic literature review," AIDS Care, vol. 21, no. 11, pp. 1343-1356, 2009.

[3] J. E. Sackoff, D. B. Hanna, M. R. Pfeiffer, and L. V. Torian, "Causes of death among persons with aids in the era of highly active antiretroviral therapy: New York City," Annals of Internal Medicine, vol. 145, no. 6, pp. 397-406, 2006.

[4] A. d'Arminio, C. A. Sabin, A. N. Phillips et al., "Cardio- and cerebrovascular events in HIV-infected persons," AIDS, vol. 18, no. 13, pp. 1811-1817, 2004.

[5] G. Guaraldi, "Cardiovascular complications in HIV-infected individuals," Current Opinion in HIV and AIDS, vol. 1, no. 6, pp. 507-513, 2006.

[6] C. U. Nduka, S. Stranges, A. M. Sarki, P. K. Kimani, and O. A. Uthman, "Evidence of increased blood pressure and hypertension risk among people living with HIV on antiretroviral therapy: a systematic review with meta-analysis," Journal of Human Hypertension, vol. 30, no. 6, pp. 355-362, 2016.

[7] C. Gazzaruso, R. Bruno, A. Garzaniti et al., "Hypertension among HIV patients: prevalence and relationships to insulin resistance and metabolic syndrome," Journal of Hypertension, vol. 21, no. 7, pp. 1377-1382, 2003.

[8] C. Jericó, H. Knobel, M. Montero et al., "Hypertension in HIVinfected patients: prevalence and related factors," American Journal of Hypertension, vol. 18, no. 11, pp. 1396-1401, 2005.

[9] B. M. Bergersen, L. Sandvik, O. Dunlop, K. Birkeland, and J. N. Bruun, "Prevalence of Hypertension in HIV-Positive Patients on Highly Active Retroviral Therapy (HAART) compared with HAART-Naïve and HIV-Negative Controls: results from a Norwegian Study of 721 patients," European Journal of Clinical Microbiology and Infectious Diseases, vol. 22, no. 12, pp. 731-736, 2003.

[10] E. C. Seaberg, A. Muñoz, M. Lu et al., "Association between highly active antiretroviral therapy and hypertension in a large cohort of men followed from 1984 to 2003," AIDS, vol. 19, no. 9, pp. 953-960, 2005.

[11] D. G. Dillon, D. Gurdasani, J. Riha et al., "Association of HIV and ART with cardiometabolic traits in sub-Saharan Africa: a systematic review and meta-analysis," International Journal of Epidemiology, vol. 42, no. 6, pp. 1754-1771, 2013.

[12] A. Malaza, J. Mossong, T. Bärnighausen, and M.-L. Newell, "Hypertension and obesity in adults living in a high HIV prevalence rural area in South Africa," PLoS ONE, vol. 7, no. 10, article e47761, 2012.

[13] O. J. Ogunmola, O. Y. Oladosu, and A. M. Olamoyegun, "Association of hypertension and obesity with HIV and antiretroviral 
therapy in a rural tertiary health center in Nigeria: a crosssectional cohort study," Vascular Health and Risk Management, vol. 10, pp. 129-137, 2014.

[14] A. G. Pacheco, S. H. Tuboi, J. C. Faulhaber, L. H. Harrison, and M. Schechter, "Increase in non-AIDS related conditions as causes of death among HIV-infected individuals in the HAART era in Brazil," PLoS ONE, vol. 3, no. 1, Article ID e1531, 2008.

[15] A. Calmy, A. Gayet-Ageron, F. Montecucco et al., "HIV increases markers of cardiovascular risk: results from a randomized, treatment interruption trial," AIDS, vol. 23, no. 8, pp. 929939, 2009.

[16] A. A. Motala, M. A. K. Omar, and F. J. Pirie, "Diabetes in Africa. Epidemiology of type 1 and type 2 diabetes in Africa," Journal of Cardiovascular Risk, vol. 10, no. 2, pp. 77-83, 2003.

[17] M. Njelekela, H. Negishi, Y. Nara et al., "Cardiovascular risk factors in Tanzania: a revisit," Acta Tropica, vol. 79, no. 3, pp. 231-239, 2001.

[18] R. Fuentes, N. Ilmaniemi, E. Laurikainen, J. Tuomilehto, and A. Nissinen, "Hypertension in developing economies: a review of population-based studies carried out from 1980 to 1998," Journal of Hypertension, vol. 18, no. 5, pp. 521-529, 2000.

[19] E. Mutimura, N. J. Crowther, A. Stewart, and W. T. Cade, "The human immunodeficiency virus and the cardiometabolic syndrome in the developing world: an African perspective," Journal of the Cardiometabolic Syndrome, vol. 3, no. 2, pp. 106110, 2008.

[20] S. Wild, G. Roglic, A. Green, R. Sicree, and H. King, "Global prevalence of diabetes: estimates for the year 2000 and projections for 2030," Diabetes Care, vol. 27, no. 10, pp. 2568-2569, 2004.

[21] A. R. Hosseinpoor, N. Bergen, S. Mendis et al., "Socioeconomic inequality in the prevalence of noncommunicable diseases in low- and middle-income countries: results from the World Health Survey," BMC Public Health, vol. 12, no. 1, article 474, 2012.

[22] S. M. Grundy, J. I. Cleeman, S. R. Daniels et al., "Diagnosis and management of the metabolic syndrome: an American Heart Association/National Heart, Lung, and Blood Institute scientific statement," Circulation, vol. 112, no. 17, pp. 2735-2752, 2005.

[23] TACAIDS, Tanzania HIV/AIDS and Malaria Indicator Survey, 2011/2012, Dar es Salaam, 2012.

[24] NACP. The United Republic of Tanzania-Ministry of Health and Social Welfare, National Guidelines for the Management of HIV and AIDS, Ministry of Health and Social Welfare, Dar es Salaam, Tanzania, 5th edition, 2015.

[25] A. V. Chobanian, G. L. Bakris, H. R. Black et al., "Seventh report of the joint national committee on prevention, detection, evaluation, and treatment of high blood pressure," Hypertension, vol. 42, no. 6, pp. 1206-1252, 2003.

[26] L. Alfredsson and A. Ahlbom, "Binomial regression in GLIM: estimating risk ratios and risk differences," American Journal of Epidemiology, vol. 125, no. 1, pp. 174-184, 1987.

[27] S. Wacholder, "Binomial regression in GLIM: estimating risk ratios and risk differences," American Journal of Epidemiology, vol. 123, no. 1, pp. 174-184, 1986.

[28] O. Miettinen, Theoretical Epidemiology, Wiley-Blackwell, New York, NY, USA, 1985.

[29] S. Muhammad, M. U. Sani, and B. N. Okeahialam, "Cardiovascular disease risk factors among HIV-infected Nigerians receiving highly active antiretroviral therapy," Nigerian Medical Journal, vol. 54, no. 3, pp. 185-190, 2013.
[30] C. A. Dimala, J. Atashili, J. C. Mbuagbaw, A. Wilfred, and G. L. Monekosso, "Prevalence of hypertension in HIV/AIDS patients on highly active antiretroviral therapy (HAART) compared with HAART-naïve patients at the limbe regional hospital, Cameroon," PLoS ONE, vol. 11, no. 2, Article ID e0148100, 2016.

[31] K. Wolf, D. A. Tsakiris, R. Weber, P. Erb, and M. Battegay, "Antiretroviral therapy reduces markers of endothelial and coagulation activation in patients infected with human immunodeficiency virus type 1,"Journal of Infectious Diseases, vol. 185, no. 4, pp. 456-462, 2002.

[32] L. G. Ekali, L. K. Johnstone, J. B. Echouffo-Tcheugui et al., "Fasting blood glucose and insulin sensitivity are unaffected by HAART duration in Cameroonians receiving first-line antiretroviral treatment," Diabetes and Metabolism, vol. 39, no. 1, pp. 71-77, 2013.

[33] J. I. Bernardino de la Serna, F. X. Zamora, M. L. Montes, J. García-Puig, and J. R. Arribas, "Hypertension, HIV infection, and highly active antiretrovíric therapy," Enfermedades Infecciosas y Microbiologia Clinica, vol. 28, no. 1, pp. 32-37, 2010.

[34] O. Jung, M. Bickel, T. Ditting et al., "Hypertension in HIV-1infected patients and its impact on renal and cardiovascular integrity," Nephrology Dialysis Transplantation, vol. 19, no. 9, pp. 2250-2258, 2004.

[35] E. Jong, S. Louw, E. C. M. Van Gorp, J. C. M. Meijers, H. Ten Cate, and B. F. Jacobson, "The effect of initiating combined antiretroviral therapy on endothelial cell activation and coagulation markers in South African HIV-infected individuals," Thrombosis and Haemostasis, vol. 104, no. 6, pp. 1228-1234, 2010.

[36] C. Fourie, J. Van Rooyen, M. Pieters, K. Conradie, T. Hoekstra, and A. Schutte, "Is HIV-1 infection associated with endothelial dysfunction in a population of African ancestry in South Africa?" Cardiovascular Journal of Africa, vol. 22, no. 3, pp. 134140, 2011.

[37] E. R. Kline and R. L. Sutliff, "The roles of HIV-1 proteins and antiretroviral drug therapy in HIV-1-associated endothelial dysfunction," Journal of Investigative Medicine, vol. 56, no. 5, pp. $752-769,2008$.

[38] D. Torre, "Nitric oxide and endothelial dysfunction in HIV type 1 infection," Clinical Infectious Diseases, vol. 43 , no. 8, pp. 10861087, 2006.

[39] C. Hawkins, G. Chalamilla, J. Okuma et al., "Sex differences in antiretroviral treatment outcomes among HIV-infected adults in an urban Tanzanian setting," AIDS, vol. 25, no. 9, pp. 1189$1197,2011$.

[40] K. A. Lichtenstein, C. Armon, K. Buchacz et al., "Low CD4+ T cell count is a risk factor for cardiovascular disease events in the HIV Outpatient Study," Clinical Infectious Diseases, vol. 51, no. 4, pp. 435-447, 2010.

[41] I. W. Manner, M. Trøseid, O. Oektedalen, M. Baekken, and I. Os, "Low nadir CD4 cell count predicts sustained hypertension in HIV-infected individuals," Journal of Clinical Hypertension, vol. 15, no. 2, pp. 101-106, 2013.

[42] R. C. Kaplan, L. A. Kingsley, S. J. Gange et al., "Low CD4+ Tcell count as a major atherosclerosis risk factor in HIV-infected women and men," AIDS, vol. 22, no. 13, pp. 1615-1624, 2008.

[43] V. A. Triant, S. Regan, H. Lee, P. E. Sax, J. B. Meigs, and S. K. Grinspoon, "Association of immunologic and virologic factors with myocardial infarction rates in a US healthcare system," Journal of Acquired Immune Deficiency Syndromes, vol. 55, no. 5, pp. 615-619, 2010. 
[44] P. Y. Hsue, S. G. Deeks, and P. W. Hunt, "Immunologic basis of cardiovascular disease in HIV-infected adults," Journal of Infectious Diseases, vol. 205, no. 3, pp. S375-S382, 2012.

[45] P. Giral, J.-F. Kahn, J.-M. André et al., "Carotid atherosclerosis is not related to past tuberculosis in hypercholesterolemic patients," Atherosclerosis, vol. 190, no. 1, pp. 150-155, 2007.

[46] C.-H. Wu, L.-S. Chen, M.-F. Yen et al., "Does non-central nervous system tuberculosis increase the risk of ischemic stroke? A population-based propensity score-matched followup study," PLoS ONE, vol. 9, no. 7, article e98158, 2014.

[47] J.-J. Sheu, H.-Y. Chiou, J.-H. Kang, Y.-H. Chen, and H.-C. Lin, "Tuberculosis and the risk of ischemic stroke: a 3-year follow-up study," Stroke, vol. 41, no. 2, pp. 244-249, 2010. 


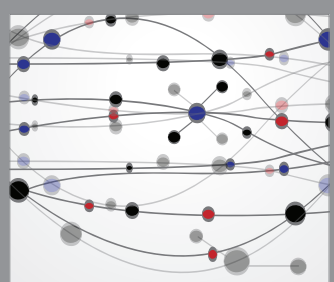

The Scientific World Journal
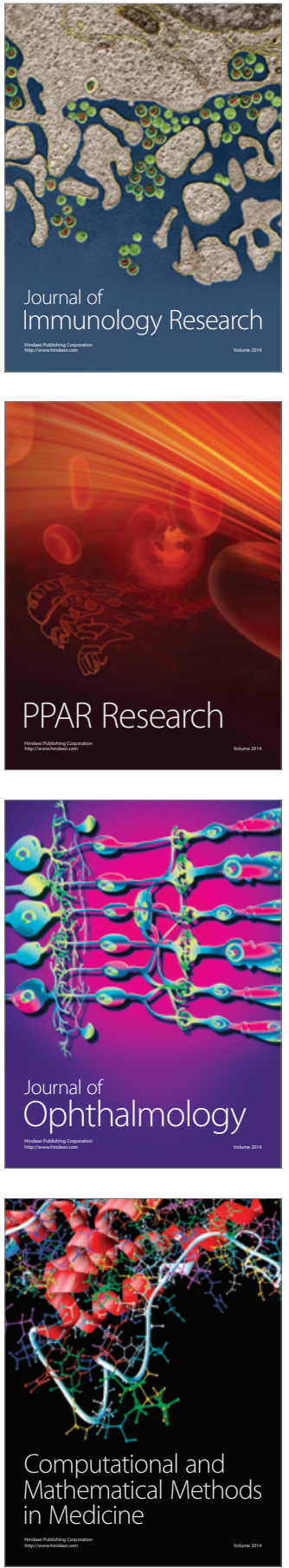

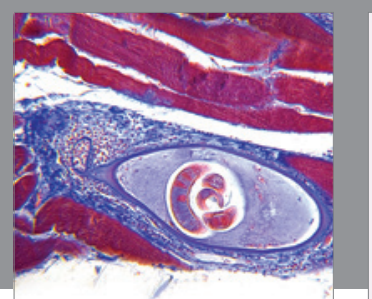

Gastroenterology Research and Practice

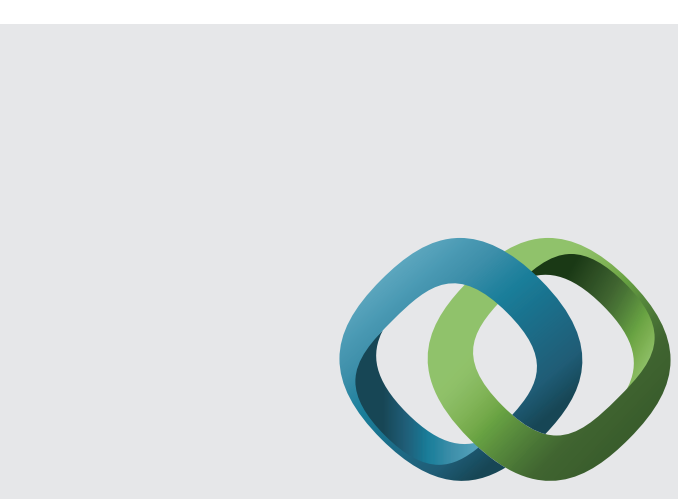

\section{Hindawi}

Submit your manuscripts at

http://www.hindawi.com
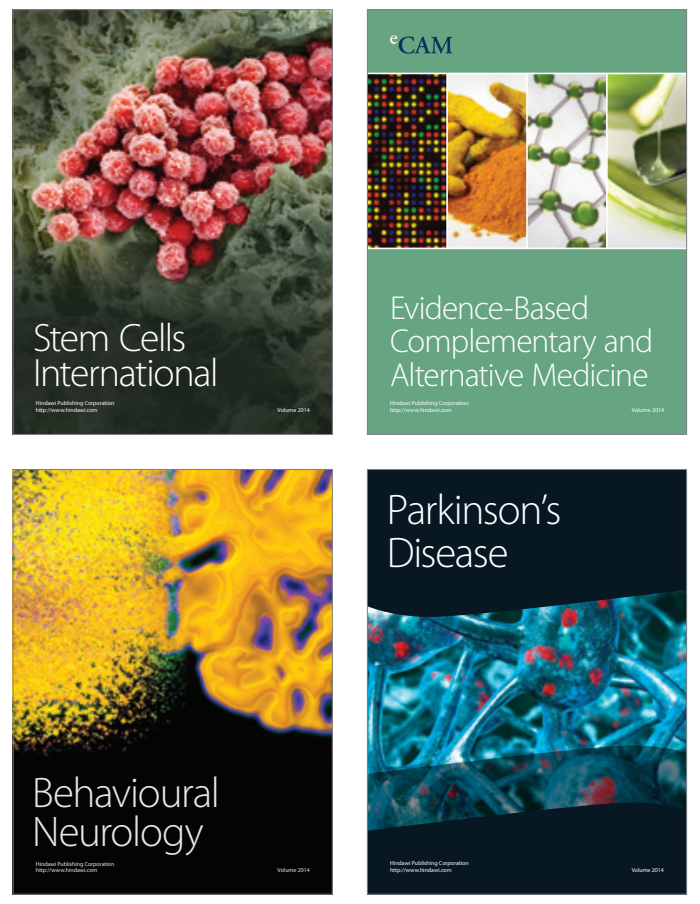
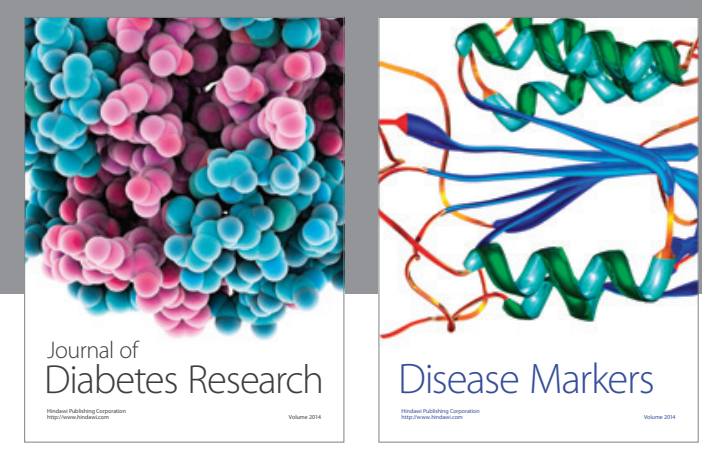

Disease Markers
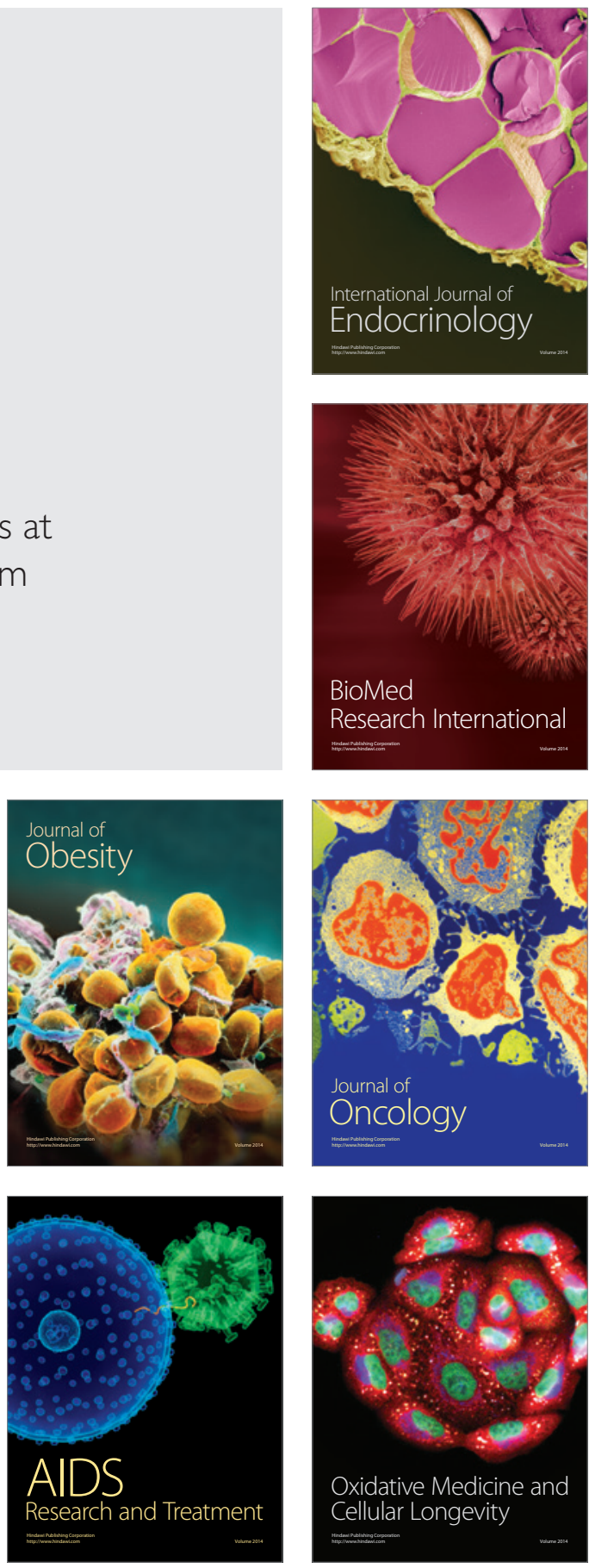